\title{
Investigating course choice motivations in university environments
}

\author{
Boxuan $\mathrm{Ma}^{{ }^{*} \mathbb{D}}, \mathrm{Min} \mathrm{Lu}^{2}$, Yuta Taniguchi ${ }^{3}$ and Shin'ichi Konomi
}

\section{${ }^{*}$ Correspondence:}

ma.boxuan.611@s.kyushu-u. ac.jp

${ }^{1}$ Graduate School

of Information Science

and Electrical Engineering,

Kyushu University, Fukuoka,

Japan

Full list of author information is available at the end of the article

\begin{abstract}
Recommendation systems need a deeper understanding of users and their motivations to improve recommendation quality and provide more personalized suggestions. This is especially true in the education domain, the more about the student is known, the more useful recommendations can be made. However, although many studies on the course recommendation exist, studies on the students' course selection motivations in universities are limited. This study investigates the factors that contribute to students' choice when selecting courses in universities to better understand student perceptions, attitudes, and needs and leverage data-driven approaches for recommending and explaining the recommendations in university environments. A qualitative interview for university students $(N=10)$ comprised of open-ended questions as well as a questionnaire for students ( $N=81$ ) was conducted, aiming to investigate the main reasons behind their choices. The results of this study show that students highly value the course contents and the benefits of the course towards their future careers. Furthermore, students are influenced by other reasons such as the possibility of obtaining a higher grade, the popularity of professors, and recommendations from peers. Next, we extract the main categories of students' motivations and analyzed the questionnaire data by employing statistical analysis methods as well as the k-means clustering algorithm to identify different types of students in terms of course selection. Based on our findings, we discuss implications for designing more personalized course recommendation systems.
\end{abstract}

Keywords: Course recommendation, University environment, Student motivation, Course selection

\section{Introduction}

Course selection is a non-trivial task. Prior to every academic term, students make a series of course selection decisions. The course selections they make create a chain of reactions that influence future course choices, skill development, and job decisions (Huang et al., 2019). Due to the increasing number of students and the rise of Massive Open Online Courses (MOOCs), course recommendation systems have been broadly applied within the context of student learning by using various data explicitly and implicitly, for instance, the data about learning activities.

Many of the recent works on course recommendation environments focus on online learning platforms such as MOOCs (Jing \& Tang 2017; Piao \& Breslin, 2016; Hou et al., author(s) and the source, provide a link to the Creative Commons licence, and indicate if changes were made. The images or other third party material in this article are included in the article's Creative Commons licence, unless indicated otherwise in a credit line to the material. If material is not included in the article's Creative Commons licence and your intended use is not permitted by statutory regulation or exceeds the permitted use, you will need to obtain permission directly from the copyright holder. To view a copy of this licence, visit http:// creativecommons.org/licenses/by/4.0/. 
2018; Zhang et al., 2017; Pang et al., 2017). These systems try to make useful suggestions proactively based on the students' contexts and profiles. However, the selection and recommendation of courses in university environments are inherently different from those in MOOCs. For example, MOOC users may have clearer learning goals than university freshmen who may still be exploring different possibilities in relation to their careers and learning (Ma et al., 2020). Also, courses in university environments are closely interwoven with various types of physical, pedagogical, and social contexts, which makes the selection and recommendation of courses in higher education a more complex task as it depends on many intertwined factors that students need to consider (Esteban et al., 2018). Current studies on course recommendation use datasets collected in physical university environments, however, they rely on recommendation approaches that are similar to the ones used in recommending MOOC courses without fully considering the versatile nature of the reasons involved in course selection in university environments. This amounts to a collaborative recommendation of the nature of "most people like you did X next." When it comes to university students' diverse intentions in selecting courses, a student's goal may not align with what most people have done (Jiang et al., 2019). Although a few existing works consider the students' motivations in university environments, they tend to make simplistic assumptions about learners and their contexts, thereby merely recommending the whole sequence of courses that satisfy the degree requirements (Parameswaran et al., 2011), or predicting the performance of students and give recommendations based on predicted results (Elbadrawy \& Karypis, 2016; Elbadrawy et al., 2015; Hu \& Rangwala, 2018; Sweeney et al., 2016).

Information about the user and the reason behind their choices is crucial for giving personalized suggestions. Users have different motivations and corresponding information needs, which refer to the rationale behind the way people behave, think, or feel at a specific time and is strongly related to the users' preferences. Therefore, user motivations are being perceived by researchers to influence the variance in the user preferences and behavior in recommendation systems, which can help match users with similar interests and even help with the cold-start problem (Jameson et al., 2003; Chen et al., 2013). It could also help improve the explainability of recommendation systems. To improve recommendation quality, recommendations need a deeper understanding of users and their motivations (McNee et al., 2006). For course recommendations in university environments, acknowledging that students have different reasons for enrolling in coursesfor example, to improve their skills, gain access to new knowledge, dabble in an area they find intriguing, or meet the requirement of graduation, and so on. However, there is a lack of study on those factors that influence students' course selection in university environments, and course recommendation methods that fully integrate with students' motivations are relatively unexplored research topics.

In order to overcome the limitations, we aim at enlightening and describing the variety of motivations among students in university environments. Our research questions in this paper are as follows:

- RQ1. General motivations: Why do students decide to take a course? What are their major motivations to choose courses? 
- RQ2. Personal differences: Do students have personal differences for those motivations?

- RQ3. What implications for course recommendation system design can be derived?

To achieve this, we employ a two-phased approach. First, qualitative interviews were conducted for 10 university students, the main goal was to gain a deep understanding of the actual reasons for taking a course. Second, we developed a questionnaire based on our interview study and used it to establish a broader understanding of the motivational factors behind the course selections of individual students. The questionnaire asks about students' opinions on the courses they have taken in the past and asked them to rate the significance of each factor behind their decision to choose each course (Note that as the student must take required courses, this study only focuses on elective courses).

The research described in this paper is a part of our larger research project that concerns with course recommendation system in university environments. In this paper, we present the results of our interviews and questionnaires to untangle the complex factors that are of concern to university students for their course selection. By finding ways to classify the reasons reliably, we will be in the position to understand the relationship between why students enroll in these courses and how they seek for the course. Using these results, we could inform the design of alternative course recommendation systems that may consider the versatile nature of reasons and students' different demands involved in course selection. In addition, instructors and course designers could use this information to improve their courses and their students' learning experiences, thus contributing to the discussion about improving instruction for diverse learners.

\section{Related work}

Several studies have sought to make sense of why students enroll in a course. Specifically, these studies include MOOCs and traditional university environments. We discuss them in the following subsections respectively.

\section{Motivations for enrollment in MOOCs}

A growing body of literature has investigated why students enroll in MOOCs. Recent work on MOOCs suggests that learners engage in a wide range of behaviors, which appear to reflect differences in motivation. Liu et al. (2015) found that the main reason for most of the students to took MOOCs could be concluded as personal interest, improve their current knowledge of the job and prepare for future job prospects. Zheng et al. (2015) conducted interviews to understand students and their reasons for enrolling in MOOCs. Their study suggested different types of students' motivation. First, some students were fulfilling their current needs, such as supplementing a for-credit course, or to help with their current position, either as students or in a workplace setting. Second, some students took the course to develop a social connection with others who shared similar interests. Third, some students enrolled in a course to prepare for future job opportunities or to gain experience in a field they might study in a more formal manner in the future. Finally, some students enrolled in a MOOC just because they were interested in satisfying their curiosity. Kizilcec and Schneider (2015) developed the Online Learning Enrollment Intentions (OLEI) questionnaire to ask students about their 
reasons for enrolling in a MOOC. These questions included career-related interests, formal education, social opportunities, potential career benefits, improve English, and so on. They also found that the subject matter of the course was indicative of the reason a student might take a MOOC. For example, students in a humanities course might have taken the course out of curiosity, while students in a social science or health-care-related course might have taken the course for career benefits (Christensen et al., 2013; Kizilcec \& Schneider, 2015).

There have been several studies that have explored the relations among students' reasons for enrolling in a MOOC, their characteristics, and achievements in MOOCs. Students' ages and genders have often been found to share a weak relationship with their reasons for enrolling in a MOOC course. Crues et al. (2018) observed that students' reasons for enrolling in a MOOC and gender did not share a significant statistical relationship. Kizilcec and Schneider (2015) have reported that females selected more reasons for enrolling in a MOOC on the OLEI scale than males. In that study, reasons for enrolling in a MOOC were found not to be related to the age of a student. de Barba et al. (2016) found that students' motivations and interests were related to how they engaged with the course's quizzes and videos. They also investigated how motivation was related to a student's final grade. Others, however, observed no relation between student motivation and the grades earned in MOOCs (Breslow et al., 2013). Crues et al. (2018) found that students' reasons for enrolling in a MOOC clustered into four interpretable reasons, and some of the reasons were related to actively engaging in portions of the course; however, these reasons were not statistically related to remaining engaged in the course overall.

In general, the literature has pointed to interesting findings in MOOCs. However, it is limited to the MOOCs which may significantly differ from the face-to-face learning in traditional university education (LaMeres \& Plumb, 2013; Nunez et al., 2016).

\section{Motivations for enrollment in university courses}

We also note that a few studies have investigated students' motivations for enrolling in courses and analyzing the students' course selection in physically co-present university classrooms.

According to Babad et al. (1999), one of the vital reasons is the characteristics of the course. McGoldrick and Schuhmann (2002) indicated that course selection is more of a function of relevance toward future careers and perceived interest in course topics. Tallón et al. (2014) conducted a survey to analyze why students choose one elective course. However, it is limited to only the case of teratology. Other study shows that students are driven both by the desire to master content because it is interesting and relevant, and by the desire to demonstrate competency to earn external recognition (Pintrich, 2003). Environmental factors, such as classroom pedagogical strategies, interact with academic and social motivations to influence learning and engagement, as do individual student characteristics (Ryan \& Deci, 2000). Shell et al. (2016) investigated the relationship between the students' entering motivation and their subsequent course achievement and retention in college CS1 courses. They measured students' course entering motivation with an instrument include: learning-approach, learning-avoid, performance-approach, performance-avoid, task-approach, and task-avoid. Their studies have found that learning approach goals were associated with higher achievement 
and retention, whereas, performance goals lead to lower achievement (Ott et al., 2015). Other studies have shown that these goals change across the semester. In addition, demographics, prior knowledge, self-perceptions, and self-regulation-the ability to plan, monitor, and control learning behaviors-have all been shown to have a salient influence on achievement (Tinto, 1997; Bransford et al., 1999; Schunk \& Zimmerman, 2012).

The literature highlights the complex reality of course selection in universities, but very little is known about the nature of these motivations, as well as their relationship to individual differences in students. Also, most studies focus on satisfying students' needs to avoid drop-out by understanding their motivations, while few studies oriented from recommending prospects. In this study, we investigate the factors that contribute to students' choice when selecting courses in universities to better understand student perceptions, attitudes, and needs and leverage data-driven approaches for recommending and explaining the recommendations in university environments. We believe that this could inform the design of course recommendation systems in university environments. Also, gaining insight on these issues is crucial for instructors and course designers to consider for attempting to improve courses.

\section{Study 1: qualitative interview}

Intuitively, the reasons behind course selection are manifold as it depends on many factors that students need to concern. Likewise, students who are enrolled in the same course may have completely different orientations. First, to get a better understanding of course selection motivations, we conducted a qualitative interview for gathering general information concerning students' opinions. We chose to use a qualitative research approach because it enables us to reveal possible hidden issues that would not unfold if using a quantitative research approach.

\section{Method}

We recruited ten participants $(\mathrm{N}=10)$ in this study using a snowball sampling method, through our social media accounts and personal friendship network, and participants are all college students. The age range between 19 and $26(\mathrm{M}=23.70, \mathrm{SD}=4.32)$. Six $(60.0 \%)$ of the interviewees were female.

We conducted a semi-structured interview and all interview questions were openended. The interview started with a brief introduction of the interviewer and a short description of the purpose and motivation of the interview. The participants were then asked about their opinions and experience on the course selection and the reasons behind their decisions to choose courses: Are you satisfied with courses you have chosen? Which experience do you have with the course selection process? What is the main reason for you to select (or not) a course? What kind of information will help you for course selection? Our particular focus was on the motivations for enrolling in a course. They are asked to give answers as honestly and truthfully as possible. Interviews ranged from approximately 35 minutes to 1 hour and the average time was nearly 45 minutes. All interviews were annotated and transcribed for data analysis. 


\section{Results}

We applied the thematic analysis to deal with the qualitative data. After transcribed the data, we first created a set of initial codes and sorted the codes into potential themes, then we reviewed and revised the theme iteratively to determined final theme. The interviews produced a rich set of recollections and descriptions addressing many issues, which have been summarized as a number of emergent themes. We identified several broad types of student motivations for enrolling courses in the following discussion. Note that although we discuss each of these themes separately, it is quite possible that a student might choose to enroll in different courses for different reasons.

\section{Personal interest}

\section{Curiosity}

Most of the participants explicitly mention their interest towards the subject as a key factor that influences their choice. Some students took courses out of curiosity simply. P2 said that "I will choose courses whose content closely related to my own interests". P8 indicates that "I choose the course because I just want to have fun".

\section{Career-related interests}

Some students took courses because they think that the knowledge or skill might be useful in the future. P3 indicates that "The courses that I am interested in and related to my major is the best choice as it can broaden my horizons and help me have a deeper understanding about my future career".

However, many students may still be exploring different possibilities in relation to their careers and learning. Especially for first-year students, they may lack learning goals and career planning for the future, and the choice of courses is aimless. Besides, physical and social university environments provide students with a plethora of opportunities to explore, discover and develop intellectual interests and meaningful goals, and student interest and goals can change as they explore and discover something meaningful. P10 mentions that "When I was a freshman, I was very confused, I did not know what I can do in the future and have no career plan".

\section{High grade}

Getting relatively high grades for students to improve their GPA is another factor that influences student's choice especially for successful students. It was mentioned by four participants. Some students even prefer to choose what they perceived would be an easier course for fear that a tougher course might lower their GPA. P7 indicates that " $I$ plan to study abroad after graduation, and an important thing for applying to my favorite school is a high GPA!".

\section{Cost avoidance}

As learning a course is a non-trivial and time-consuming task, it is expected that some students desire to get through the class with as little time and effort as possible, and 7 participants mentioned this. P4 indicates that "Although some courses seem very interesting, I will not choose them if I heard that the homework is particularly heavy and the 
instructors are very strict". P1 mentions that "I don't want to choose difficult courses, I want to choose courses that I am good at and could give full play to my strengths".

\section{Social aspect}

\section{Collaborative Learning}

Six students mentioned that they would like to enroll in a course with their friends or classmates together. Potts et al. (2018) conclude that the risk of social isolation is a problem in the learning process especially for first-year students at university, who have difficulty navigating their new academic and new environment. Social factor also plays a part in course selection process. Tinto (1997) concludes that participation in a collaborative learning group enables students to develop a network of support. This community of classroom-based peers (the network of support) encourages student's attendance and class participation. P9 indicates that "If I could have a class with my friends, I will not feel nervous or anxious. We can sit together, discuss together, and help each other."

\section{Social ties}

The social ties of classmates and friends can be important and some students are highly influenced by their peers' comments and recommendations when it comes to choosing the most suitable course. Professors' popularity was also highlighted by several students as a reason for course choice. Osborne et al. (2003) concluded that the teacher facilitating a course is a significant factor that can change students' attitudes towards a course, instead of the course itself. P10 indicates that "I will follow the suggestions of senior students, they have taken some classes and are more experienced. They can tell me which instructors are good at teaching and which courses have less homework".

In addition, there were other reasons, such as location, time, job-related commitments, and the physical facility such as air conditioner and WiFi connectivity. It is worthwhile to note that many students gave more than one reason, which indicates the complexity of the problem.

\section{Study 2: questionnaire}

The interview results have revealed various reasons for course selection and allowed us to extract potential factors for course recommendations in university environments. In order to answer the research questions of this study, we conducted a relatively larger scale user study.

\section{Method}

We designed a 5-Likert scale (1-completely disagree, 5-completely agree) questionnaire regarding student motivations in terms of course selection behavior based on information collected by interviews and the OLEI questionnaire (Kizilcec \& Schneider, 2015). The questionnaire included both closed-ended and open-ended questions. Closedended questions are presented in Table 1 and the open-ended question is used as "Other reason, what"-type.

The questionnaire was sent to all $(\mathrm{N}=336)$ students from courses for freshmen in our university and respondents are asked to rate the importance of each factor in selecting courses. Finally, 24.1 ( $\mathrm{N}=81)$ of students responded to the questionnaire. Most of them were first-year students (96.4\%), 34.6\% were female and $65.4 \%$ were male, which 
Table 1 Questionnaire regarding course selection

\begin{tabular}{llll}
\hline Item & Description $^{\text {a }}$ & Item & Description \\
\hline Q1 & If it's easy to get a credit & Q10 & If the course's instructor is good at teaching \\
Q2 & If it's easy to get a good grade & Q11 & If one is compatible with the course's instructor \\
Q3 & If the difficulty level of the course is appropriate & Q12 & If the course is fun \\
Q4 $\quad$ If one can acquire knowledge and improve & Q13 & If the course takes place at an appropriate time \\
& competency & Q14 & If friends take the course \\
Q5 $\quad$ If the course is useful in one's future career & Q15 & If one can make friends as a result of taking the \\
Q6 $\quad$ If the course is interesting & & course \\
& & Q16 & If the amount of homework is appropriate \\
Q7 $\quad$ If friends recommend the course & Q17 & if the course's physical environment is good \\
Q8 & If senior students recommend the course & Q18 & If one has clear goal \\
Q9 & If instructors recommend the course & &
\end{tabular}

${ }^{a}$ These are the English translation, which is originally in Japanese

${ }^{\mathrm{b}}$ Such as temperature, humidity, WiFi connectivity

Completely Disagree $\square$ Disagree $\square$ Neutrals $\square$ Agree Completely Agree

Q6 If the course is interesting

Q12 If the course is fun

Q2 If it's easy to get a good grade

Q4 If one can acquire knowledge and improve competency

Q1 If it's easy to get a credit

Q5 If the course is useful in one's future career

Q13 If the course takes place at an appropriate time

Q3 If the difficulty level of the course is appropriate

Q10 If the course's instructor is good at teaching

Q11 If one is compatible with the course's instructor

Q16 If the amount of homework is appropriate

Q17 If the course's physical environment is good

Q18 If one has clear goal

Q14 If friends take the course

Q8 If senior students recommend the course

Q7 If friends recommend the course

Q9 If instructors recommend the course

Q15 If one can make friends as a result of taking the course

Fig. 1 The questionnaire results

\begin{tabular}{|c|c|c|c|}
\hline $7 \%$ & & $33 \%$ & $57 \%$ \\
\hline & & $27 \%$ & $54 \%$ \\
\hline & & $25 \%$ & $49 \%$ \\
\hline $15 \%$ & & $37 \%$ & $47 \%$ \\
\hline $7 \%$ & $19 \%$ & $28 \%$ & $42 \%$ \\
\hline $11 \%$ & $20 \%$ & $27 \%$ & $41 \%$ \\
\hline $10 \%$ & $15 \%$ & $28 \%$ & $41 \%$ \\
\hline
\end{tabular}

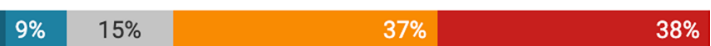

\begin{tabular}{|l|l|l|}
\hline $11 \%$ & $43 \%$ & $37 \%$ \\
\hline
\end{tabular}

\begin{tabular}{l|l|l|l}
$10 \%$ & $12 \%$ & $38 \%$ & $35 \%$
\end{tabular}

\begin{tabular}{l|l|l|l}
\hline $15 \%$ & $14 \%$ & $42 \%$ & $30 \%$
\end{tabular}

\begin{tabular}{|c|c|c|c|c|c|}
\hline $12 \%$ & $22 \%$ & $17 \%$ & & $30 \%$ & $19 \%$ \\
\hline $16 \%$ & $26 \%$ & & & $41 \%$ & $16 \%$ \\
\hline $22 \%$ & $26 \%$ & & $14 \%$ & $25 \%$ & $14 \%$ \\
\hline $15 \%$ & $10 \%$ & $27 \%$ & & $36 \%$ & $12 \%$ \\
\hline $15 \%$ & $20 \%$ & $25 \%$ & & & \\
\hline $15 \%$ & $22 \%$ & & $35 \%$ & & \\
\hline $40 \%$ & & $26 \%$ & & $22 \%$ & $11 \%$ \\
\hline
\end{tabular}
$\%$ 


\section{Results}

The results shown in Fig. 1 indicate that many factors affect students' decision to choose courses. Among them, the overall most important factor was students' interest (Q6). Furthermore, the factors such as usefulness for career (Q5), good grades (Q2), and easiness to get credit (Q1) are perceived to be important in course selection. From the above results, one safe conclusion can be drawn that there are complex constraints and contexts that must be considered together and students have to balance all those factors to make their final decisions.

\section{Gender difference}

First, we analyze the data to understand the gender differences regarding the questionnaire using the independent sample t-test. As Fig. 2 shows, male students prefer to enroll in a course with their friends (Q14, M_male = 3, M_female $=2.5, p<0.1$ ), or want to make friends as a result of taking the course $\left(\mathrm{Q} 15, \mathrm{M} \_\right.$male $=2.2$, M_female $=1.8$, $p<0.05)$. Also, they seem to consider more about the course's physical environment (Q17, M_male $=3.5$, M_female $=2.7, p<0.1$ ). There is no significant difference between female students and male students in other questions.

\section{Clear learning goal versus unclear learning goal}

Answer to Q18 revealed that 17.2\% of first-year students are either very unclear or unclear about their learning goals, and $26 \%$ of first-year students are neutrals about this question, the choice of courses for those students is aimless. The students with clear learning goals and the students without clear learning goals may have different criteria

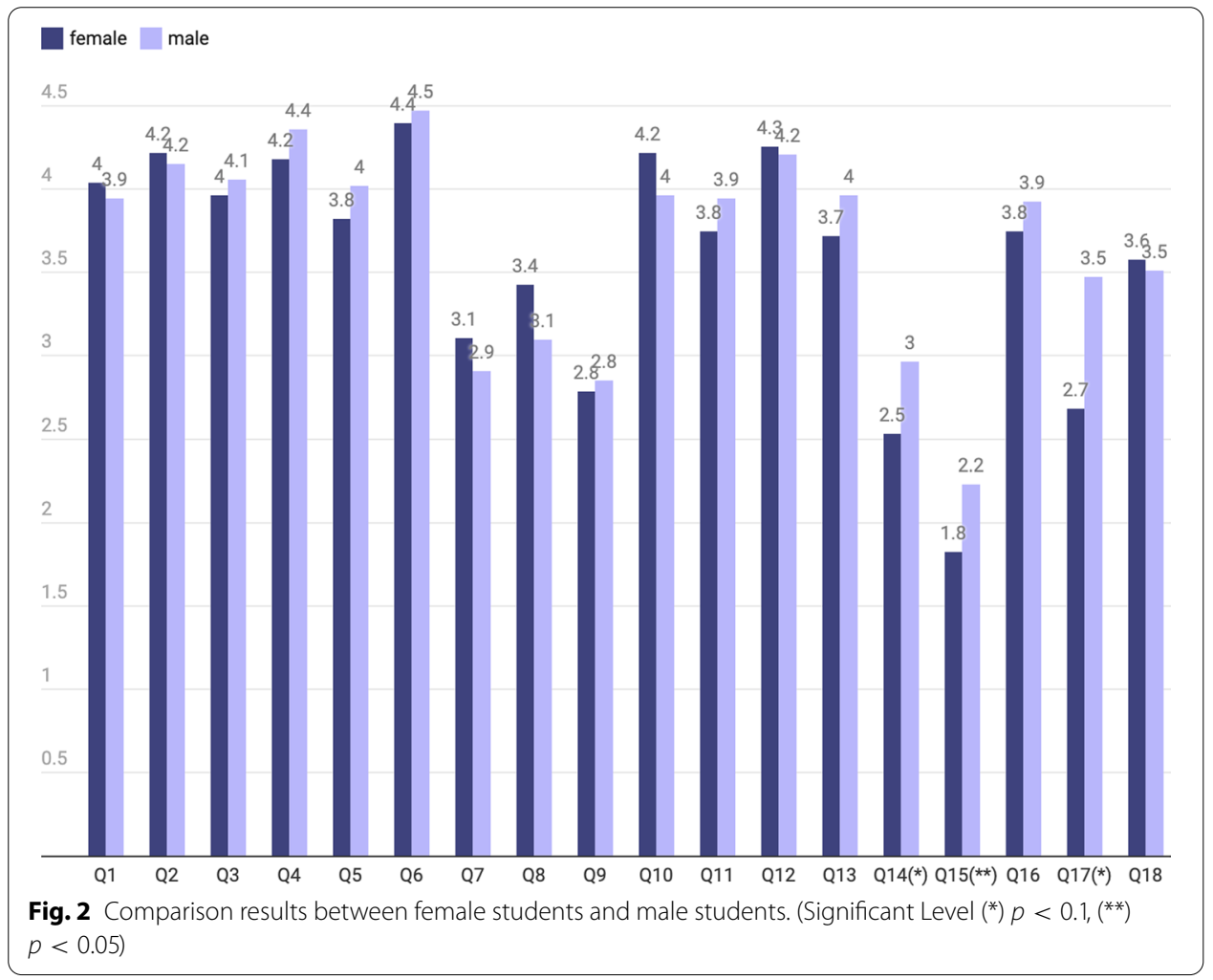




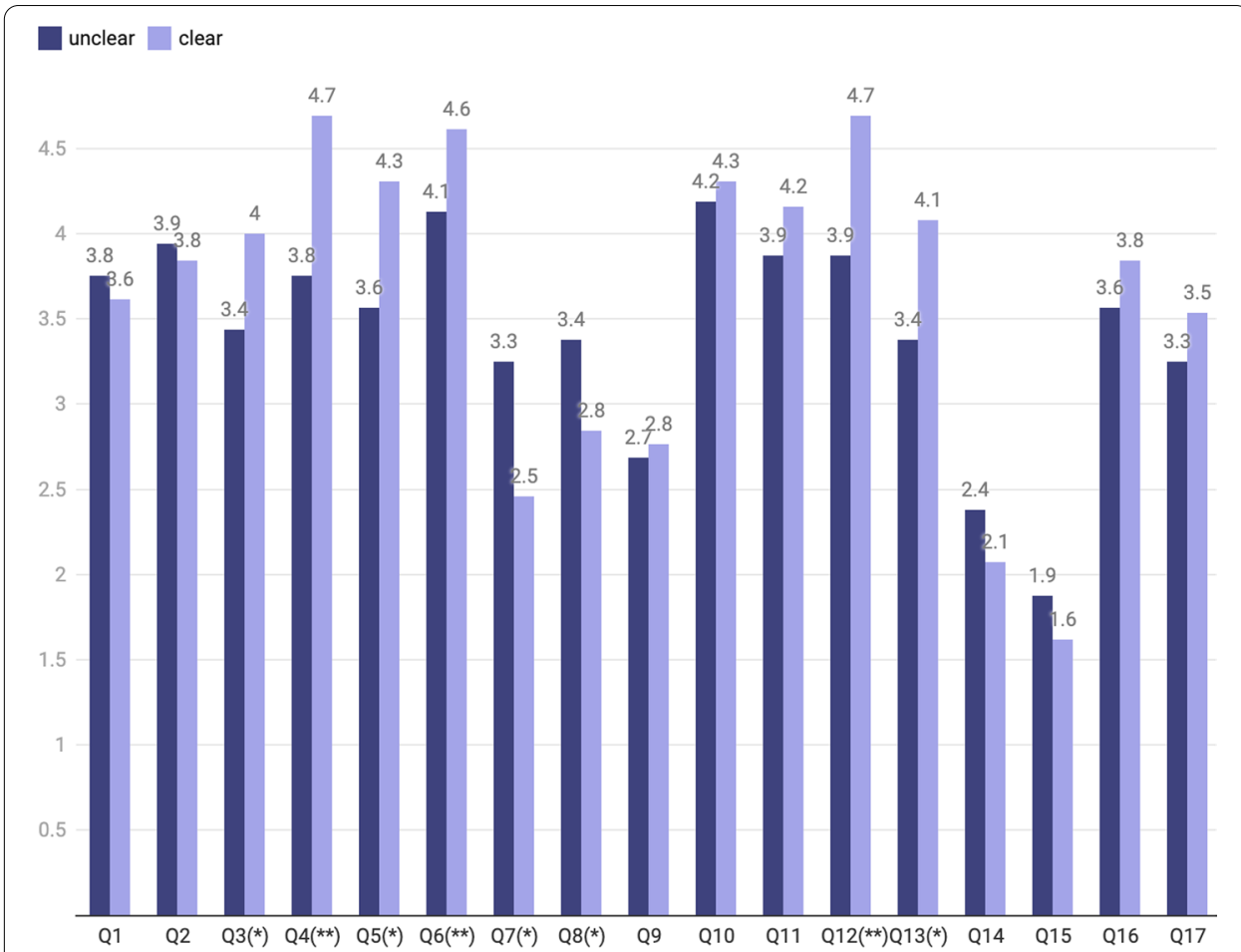

Fig. 3 Comparison results between students with clear learning goals and students without clear learning goals. (Significant Level $\left.{ }^{*}\right) p<0.1,\left({ }^{* *}\right) p<0.05$ )

for course selection. To have a clear view, we analyze the data to compare these two groups.

Figure 3 shows the results using the independent sample t-test. Students with clear learning goals highly value the knowledge $\left(\mathrm{Q} 4, \mathrm{M} \_\right.$clear $=4.7$, M_unclear $=3.8$, $p<0.05)$, and consider usefulness and relevance to their future goals (Q5, M clear $=4.3$, M_unclear $=3.6, p<0.1$ ) are important in course selection. They prefer to take a course if they are interested in it $\left(\mathrm{Q} 6, \mathrm{M} \_\right.$clear $=4.6, \mathrm{M} \_$unclear $\left.=4.1, p<0.05\right)$ or if they think it is fun (Q12, M_clear $=4.7$, M_unclear $=3.9, p<0.05)$. Besides, the difficulty level of the course (Q3, M_clear $=4$, M_unclear $=3.4, p<0.1)$ and appropriate time $(\mathrm{Q} 13$, M_clear $=4.1$, M_unclear $=3.4, p<0.1)$ is highly rated by them. It may be because students with clear learning goals tend to manage their time and plan their future. In contrast, students without clear goals may be inclined to exploit social means of obtaining recommendations more than the students with clear goals. They might consider more about suggestions from their friends (Q7, M_clear $=2.5$, M_unclear $=3.3$, $p<0.1$ ) and senior students (Q8, M_clear $=2.8$, M_unclear $=3.4, p<0.1)$.

\section{Clustering result}

Finally, we analyzed the collected data by employing the k-means clustering algorithm to identify different types of students in terms of course selection motivations. In order to identify the optimal number of clusters, we have performed the elbow method (Bholowalia \& Kumar, 2014) and the right number of clusters could be 4 . 
Table 2 Results of clustering analysis

\begin{tabular}{llllll}
\hline Item & Description & Cluster 1 & Cluster 2 & Cluster 3 & Cluster 4 \\
\hline Q1 & If it's easy to get a credit & 3.25 & $\mathbf{4 . 5 4}$ & 3.32 & 3.80 \\
Q2 & If it's easy to get a good grade & 4.34 & $\mathbf{4 . 6 3}$ & 3.60 & 4.00 \\
Q3 & If the difficulty level of the course is appropriate & 3.82 & $\mathbf{4 . 3 4}$ & 3.75 & 4.13 \\
Q4 & If one can acquire knowledge and improve competency & 3.50 & 3.55 & $\mathbf{4 . 6 1}$ & 4.44 \\
Q5 & If the course is useful in one's future career & 4.40 & 3.13 & $\mathbf{4 . 5 0}$ & 4.31 \\
Q6 & If the course is interesting & 4.00 & 3.81 & $\mathbf{4 . 6 1}$ & 4.17 \\
Q7 & If friends recommend the course & 3.93 & 3.64 & 2.18 & $\mathbf{4 . 7 5}$ \\
Q8 & If senior students recommend the course & 1.50 & 3.85 & 2.25 & $\mathbf{4 . 4 1}$ \\
Q9 & If instructors recommend the course & 2.25 & 2.91 & 2.61 & $\mathbf{3 . 6 8}$ \\
Q10 & If the course's instructor is good at teaching & 1.00 & 3.82 & $\mathbf{4 . 1 4}$ & 3.88 \\
Q11 & If one is compatible with the course's instructor & 3.75 & 3.23 & 3.89 & $\mathbf{4 . 3 2}$ \\
Q12 & If the course is fun & 3.25 & 3.55 & $\mathbf{4 . 6 1}$ & 4.34 \\
Q13 & If the course takes place at an appropriate time & 2.75 & 3.32 & 3.79 & $\mathbf{4 . 2 9}$ \\
Q14 & If friends take the course & 3.00 & 2.82 & 1.86 & $\mathbf{4 . 3 7}$ \\
Q15 & If one can make friends as a result of taking the course & 1.50 & 1.55 & 1.57 & $\mathbf{3 . 5 1}$ \\
Q16 & If the amount of homework is appropriate & 1.25 & $\mathbf{3 . 7 3}$ & 3.43 & 3.61 \\
Q17 & if the course's physical environment is good & 3.25 & 2.50 & 2.86 & $\mathbf{4 . 3 2}$ \\
\hline
\end{tabular}

The largest value in each row is highlighted with bold text

Table 2 shows the clustering results. It can be seen that both cluster 1 and cluster 2 are highly motivated by grades, but students of cluster 1 seem to want to make a trade-off among high grades $(\mathrm{Q} 2, \mathrm{M}=4.34)$, usefulness $(\mathrm{Q} 5, \mathrm{M}=4.40)$, and their interests ( $\mathrm{Q} 6$, $\mathrm{M}=4.00$ ), while students of cluster 2 seem to be grade-oriented type as they consider high grades are the most important factors ( $\mathrm{Q} 2, \mathrm{M}=4.63)$. Also, they consider more about the difficulty level (Q3, $\mathrm{M}=4.34)$ and the amount of homework (Q16, $\mathrm{M}=3.73$ ) in the courses, and they are inclined to choose courses that do not require too much effort. In contrast to cluster 2, students of cluster 3 seem to be learning-oriented as grades aren't that important for them $(\mathrm{Q} 2, \mathrm{M}=3.60)$. Students of this cluster probably prefer to choose courses to seriously study knowledge and are mainly interested in learning and mastering content or a given skill. Besides, they consider mistakes and failure as learning opportunities, therefore, they may even take difficult courses (Q3, $M=3.75)$ if they are interested in them $(\mathrm{Q} 6, \mathrm{M}=4.61)$ or think the course is useful for them (Q5, $M=4.50$ ). Another interesting phenomenon is about students in cluster 4. Their average rating of social aspect is much higher than all the other clusters. They appreciate the courses recommended by their friends ( $\mathrm{Q} 7, \mathrm{M}=4.75)$, senior students $(\mathrm{Q} 8, \mathrm{M}=4.41)$, and instructors $(\mathrm{Q} 9, \mathrm{M}=3.68)$. They also highly value the student-teacher compatibility $(\mathrm{Q} 11, \mathrm{M}=4.32)$. In addition, they prefer to enroll in a course with their friends (Q14, $\mathrm{M}=4.37$ ) or want to meet friends with similar interests ( $\mathrm{Q} 15, \mathrm{M}=3.51)$.

\section{Motivation structure}

In this subsection, we investigate the factor structure of these motivations by using Exploratory Factor Analysis (EFA) and Confirmatory Factor Analysis (CFA) method to identify the underlying relationships between measured motivations. 


\section{Exploratory factor analysis}

First, we have examined skewness and kurtosis values. Most variables' skewness and kurtosis values are between -1 and 1 , which means the data is normally distributed. Besides, the result of Kaiser-Meyer-Olkin Measure value is .647 , above the commonly recommended value of .6, and Bartlett's test of sphericity is significant $(p<0.05)$, which indicates the sample used was adequate. Also, the communalities were all above .5, further confirming that each item shared some common variance with other items.

A scree plot analysis was performed to determine the number of factors that would be optimal given the covariance structure of the data. The scree plot analysis suggested that the optimal number of factors is five. A factor analysis of the combined correlation matrix with five factors accounted for $63 \%$ of the variance. These factors are course quality, recommendation from others, context and setting of the course, social aspect, and effort needed. A varimax rotation provided the best-defined factor structure. The factor loading matrix for this final solution is presented in Table 3.

Table 3 Factor loadings and communalities based on a principal components analysis with varimax rotation

\begin{tabular}{|c|c|c|c|c|c|c|}
\hline Item & Description & Course quality & Recommendation & $\begin{array}{l}\text { Context } \\
\text { and } \\
\text { setting }\end{array}$ & Social aspect & Effort \\
\hline Q10 & $\begin{array}{l}\text { If the course's instructor is } \\
\text { good at teaching }\end{array}$ & 0.712 & 0.391 & & & \\
\hline Q4 & $\begin{array}{l}\text { If one can acquire } \\
\text { knowledge and improve } \\
\text { competency }\end{array}$ & 0.707 & & & & \\
\hline Q11 & $\begin{array}{l}\text { If one is compatible with } \\
\text { the course's instructor }\end{array}$ & 0.660 & & 0.309 & & \\
\hline Q5 & $\begin{array}{l}\text { If the course is useful in } \\
\text { one's future career }\end{array}$ & 0.643 & & & & \\
\hline Q6 & If the course is interesting & 0.640 & -0.307 & & & \\
\hline Q12 & If the course is fun & 0.515 & & 0.336 & 0.344 & -0.338 \\
\hline Q7 & $\begin{array}{l}\text { If friends recommend the } \\
\text { course }\end{array}$ & & 0.838 & & & \\
\hline Q8 & $\begin{array}{l}\text { If senior students recom- } \\
\text { mend the course }\end{array}$ & & 0.782 & & & 0.346 \\
\hline Q9 & $\begin{array}{l}\text { If instructors recommend } \\
\text { the course }\end{array}$ & & 0.690 & & & \\
\hline Q3 & $\begin{array}{l}\text { If the difficulty level of the } \\
\text { course is appropriate }\end{array}$ & & & 0.478 & & 0.356 \\
\hline Q15 & $\begin{array}{l}\text { If one can make friends as a } \\
\text { result of taking the course }\end{array}$ & & & & 0.746 & \\
\hline Q17 & $\begin{array}{l}\text { if the course's physical } \\
\text { environment is good }\end{array}$ & & & 0.738 & & \\
\hline Q16 & $\begin{array}{l}\text { If the amount of homework } \\
\text { is appropriate }\end{array}$ & & & 0.694 & & 0.484 \\
\hline Q13 & $\begin{array}{l}\text { If the course takes place at } \\
\text { an appropriate time }\end{array}$ & & & 0.578 & 0.327 & \\
\hline Q14 & If friends take the course & & 0.467 & & 0.569 & \\
\hline Q18 & If one has clear goal & & & & 0.716 & \\
\hline Q1 & If it's easy to get a credit & & & & & 0.612 \\
\hline Q2 & $\begin{array}{l}\text { If it's easy to get a good } \\
\text { grade }\end{array}$ & & & & & 0.761 \\
\hline
\end{tabular}


Table 4 Model fit summary

\begin{tabular}{ll}
\hline Fit statistic & Value \\
\hline Chi2 $(d f)$ & $253.480(45)$ \\
RMSEA & 0.097 \\
$(90 \%$ Cl $)$ & $(0.051,0.141)$ \\
AIC & 273.480 \\
BIC & 276.668 \\
CFI & 0.905 \\
GFI & 0.891 \\
TLI & 0.896 \\
\hline
\end{tabular}

Table 5 AVE and CR result

\begin{tabular}{lll}
\hline Factor & AVE & CR \\
\hline Factor1 & 0.505 & 0.743 \\
Factor2 & 0.498 & 0.662 \\
Factor3 & 0.505 & 0.759 \\
Factor4 & 0.635 & 0.702 \\
Factor5 & 0.719 & 0.802 \\
\hline
\end{tabular}

\section{Confirmatory factor analysis}

We also performed Confirmatory factor analysis (CFA) to confirms the factor structures. Goodness-of-fit statistics were obtained, as can be seen in Tables 4 and 5 .

\section{Discussion}

\section{Answering the research questions}

In this section, we discuss the results of the interview and questionnaire, and we link them together to answer our research questions.

\section{General motivations ( $R Q 1)$}

In summary, the results of our studies indicate that many factors affect students' decision to choose courses. Among them, the overall most important factor was students' interest. Furthermore, the factors such as usefulness for one's future career, good grades, and easiness to get credit are perceived to be important in course selection. In addition, there were other reasons, such as location, time, job-related commitments, and the physical facility such as air conditioner. It is worthwhile to note that many students gave more than one reason and students must balance all these complex constraints and contexts together to make their decisions. Also, different students have different ranking strategies as their own criteria.

\section{Personal differences (RQ2)}

Align with the previous study (Crues et al., 2018),we can observe only a few differences with respect to the gender of different participants. Male students seem are more 
socially engaged as they would like to enroll in a course with their friends or want to make friends with others. Also, they emphasize more about the course's physical environment than female students.

We do see differences in subjective responses in relation to the clear learning goals of participants. Students with clear learning goals consider the knowledge, usefulness, and relevance to their future careers are important in course selection. They would rather take a course for fun and interesting. Besides, the difficulty level of the course and appropriate time is highly rated by them. In contrast, students without clear goals may be inclined to exploit social means of obtaining recommendations suggestions from their friends and senior students.

We identify four different types of students in terms of course selection. (a) All-around type: They want to make a trade-off among high grades, usefulness, and their interests. (b) Grade-oriented: They consider high grades are the most important factor. Also, they seem to be task- or work-avoid because they consider more about the difficulty level and the amount of homework in the courses, reflect a desire to get through the class with as little time and effort as possible. (c) Learning-oriented: Grades aren't that important for them. They probably would like to choose courses to seriously study knowledge and are mainly interested in learning and mastering content or a given skill. Besides, they may even challenge difficult courses if they are interested in them or think the course is useful for them. (d) Social-oriented: They consider more about suggestions from their friends appreciate the courses recommended by their friends, senior students, and instructors. They also highly value student-teacher compatibility. In addition, they prefer to enroll in a course with their friends or want to meet friends with similar interests.

\section{Implications for course recommendation system develop (RQ3)}

Student motivations are a useful lens for understanding students and inform design directions for course recommendation systems.

Multi-criteria personalized recommendation First, a useful course recommendation system should better account for student motivations in their designs. Results of our studies show that different students may have completely different orientations based on their own reasons, which serve as different criteria for course selection and those should be considered in course recommendation systems in physically-based university environments. This suggests that recommendations that are aimed only at one or a few factors are likely not enough to help the students find useful courses. Also, take different factors into account when training models may get better results (Esteban et al., 2018). In addition, individual differences indicate the need of designing a personalized system to fit different students (Esteban et al., 2018).

Utilize social information A substantial number of students were found to take courses for social reasons, even though the learning experience was designed primarily for individuals. Many course recommendation systems separate social features, even though learners can be an invaluable resource to each other. Our results indicate that, in such physically-based learning environments, students would ask their peers, mentors, or senior students to recommend courses for them. Such social information can be extremely useful and could be considered for future course recommendation systems. 
Issue warnings and provide preparatory Another finding is, in universities, the cost to students of making a bad decision is much higher as it can have a long-lasting effect on the student and seriously affect their course achievements. As a result, a lot of students were found to care about their GPA. In such a situation, if a course recommender system could issue a warning for courses too advanced and provide suitable preparatory courses would therefore be extremely beneficial.

Support exploration and explanation Also, course recommendation systems should support exploring and provide relevant information to explain the recommendations. Our results indicate that some students may have no clear idea of what they want to study. For those students, course recommendations that help to explore various candidate courses can be extremely important. In addition, have a good understanding of why they should take the course is important to help them with the decision process. Explain the reason why the course is recommended could increase student's trust in the system, improve their understanding of the course content and knowledge structure, persuade them to accept the course. Also, it enables students to develop their own vision, reasoning and finally pave their way for future learning goals and career plans.

Provide user control Finally, allowing students to involve in the recommendation process is another strategy for supporting the transparent and diversity of student needs. For example, allow students to provide feedback in the recommendation process by choosing different criteria for recommendation and changing the influence of selected criteria. There are some recommendation systems allowing user intervention into the recommendation processes by rating, removing, sorting recommended items, or editing input data sources (Tsai \& Brusilovsky 2018; Bostandjiev et al., 2012; Parra \& Brusilovsky, 2015). Although they are not designed for education domains, those works propose a good solution and provide insights for educational course selections.

\section{Limitations}

Although conducted on a relatively small-scale, our study has revealed the complexity and variety of factors involved in students' decision to choose courses in university environments. The main limitation of our work is that conclusions are based on data that was collected in our university. This challenges the generalizability of our findings, we will carry out a more large-scale study on students' selection decisions as future work.

\section{Conclusion}

In this paper, we present the results of our interviews and questionnaires to untangle the complex factors that are of concern to university students for their course selection. Our study has revealed the complexity and variety of factors involved in students' decision to choose courses in university environments. Students who enrolled in the same course may have completely different orientations, and those should be considered in course recommendation systems in physically-based university environments. Using these results, we could inform the design of alternative course recommendation systems that may consider the versatile nature of reasons and students' different demands involved in course selection. In addition, instructors and course designers could use this 
information to improve their courses and their students' learning experiences, thus contributing to the discussion about improving instruction for diverse learners.

Future work should examine other factors that affect both behavioral choices and motivations. Beyond demographic differences, levels of prior knowledge, preference, and learning style are other individual differences between students that have been identified as important. A final topic for further investigation is the extent to which the suggested design changes for course recommendation systems could actually measuring and accounting for individual differences and supporting students with specific motivations. Based on those results, we could design and develop a better course recommendation system.

\section{Abbreviations}

MOOCs: Massive Open Online Courses; OLEl: Online Learning Enrollment Intentions.

Acknowledgements

The authors would like to thank the participants in our experiment.

\section{Authors' contributions}

This study reported in this article is a part of the Ph.D. project conducted by BM. SK is his supervisor. An initial manuscript was written by BM. SK has a significant contribution to plan and prepare the materials for conducting the experiment, recruiting participants, and reviewing the manuscript. ML and YT have significant contributions to provide feedback to analyze the data and review the manuscript. Each named author has substantially contributed to conducting the underlying research. All authors read and approved the final manuscript.

Funding

This work was supported by JSPS KAKENHI Grant Nos. JP16H06304, JP2OH00622, JP20K19939.

\section{Availability of data and materials}

Data and material are not available as our consent forms did not include information regarding sharing data outside of the research study.

\section{Declarations}

\section{Competing interests}

The authors declare that they have no competing interests.

\section{Author details}

${ }^{1}$ Graduate School of Information Science and Electrical Engineering, Kyushu University, Fukuoka, Japan. ${ }^{2}$ Faculty of Arts and Science, Kyushu University, Fukuoka, Japan. ${ }^{3}$ Research Institute for Information Technology, Kyushu University, Fukuoka, Japan.

Received: 25 May 2021 Accepted: 17 November 2021

Published online: 27 November 2021

\section{References}

Babad, E., Darley, J. M., \& Kaplowitz, H. (1999). Developmental aspects in students' course selection. Journal of Educational Psychology, 91(1), 157.

Bholowalia, P., \& Kumar, A. (2014). EBK-means: A clustering technique based on elbow method and K-means in WSN. International Journal of Computer Applications, 105(9), 17-24.

Bostandjiev, S., O'Donovan, J., \& Höllerer, T. (2012). Tasteweights: A visual interactive hybrid recommender system. In Proceedings of the sixth ACM conference on recommender systems (pp. 35-42).

Bransford, J., Bransford, J. D., Brown, A. L., \& Cocking, R. R. (1999). How people learn: Brain, mind, experience, and school. National Academies Press.

Breslow, L., Pritchard, D. E., DeBoer, J., Stump, G. S., Ho, A. D., \& Seaton, D. T. (2013). Studying learning in the worldwide classroom research into edX's first MOOC. Research \& Practice in Assessment, 8, 13-25.

Chen, L., Wu, W., \& He, L. (2013). How personality influences users' needs for recommendation diversity? In CHI'13 extended abstracts on human factors in computing systems (pp. 829-834).

Christensen, G., Steinmetz, A., Alcorn, B., Bennett, A., Woods, D., \& Emanuel, E. (2013). The MOOC phenomenon: Who takes massive open online courses and why? Available at SSRN 2350964.

Crues, R. W., Henricks, G. M., Perry, M., Bhat, S., Anderson, C. J., Shaik, N., \& Angrave, L. (2018). How do gender, learning goals, and forum participation predict persistence in a computer science MOOC? ACM Transactions on Computing Education (TOCE), 18(4), 1-14. 
de Barba, P. G., Kennedy, G. E., \& Ainley, M. (2016). The role of students' motivation and participation in predicting performance in a MOOC. Journal of Computer Assisted Learning, 32(3), 218-231.

Elbadrawy, A., \& Karypis, G. (2016). Domain-aware grade prediction and top-n course recommendation. In Proceedings of the 10th ACM conference on recommender systems (pp. 183-190).

Elbadrawy, A., Studham, R. S., \& Karypis, G. (2015). Collaborative multi-regression models for predicting students' performance in course activities. In Proceedings of the fifth international conference on learning analytics and knowledge (pp. 103-107).

Esteban, A., Zafra, A., \& Romero, C. (2018). A hybrid multi-criteria approach using a genetic algorithm for recommending courses to university students. In International educational data mining society.

Hou, Y., Zhou, P., Xu, J., \& Wu, D. O. (2018). Course recommendation of MOOC with big data support: A contextual online learning approach. In IEEE INFOCOM 2018-IEEE conference on computer communications workshops (INFOCOM WKSHPS) (pp 106-111). IEEE.

Hu, Q., \& Rangwala, H. (2018). Course-specific Markovian models for grade prediction. In Pacific-Asia conference on knowledge discovery and data mining (pp. 29-41). Springer.

Huang, L., Wang, C.-D., Chao, H.-Y., Lai, J.-H., \& Philip, S. Y. (2019). A score prediction approach for optional course recommendation via cross-user-domain collaborative filtering. IEEE Access, 7, 19550-19563.

Jameson, A., Baldes, S., \& Kleinbauer, T. (2003). Enhancing mutual awareness in group recommender systems. In Proceedings of the IJCAI.

Jiang, W., Pardos, Z. A., \& Wei, Q. (2019). Goal-based course recommendation. In Proceedings of the 9th international conference on learning analytics \& knowledge (pp. 36-45).

Jing, X., \& Tang, J. (2017). Guess you like: Course recommendation in MOOCs. In Proceedings of the international conference on web intelligence (pp. 783-789).

Kizilcec, R. F., \& Schneider, E. (2015). Motivation as a lens to understand online learners: Toward data-driven design with the OLEI scale. ACM Transactions on Computer-Human Interaction (TOCHI), 22(2), 1-24.

LaMeres, B. J., \& Plumb, C. (2013). Comparing online to face-to-face delivery of undergraduate digital circuits content. IEEE Transactions on Education, 57(2), 99-106.

Liu, M., Kang, J., \& McKelroy, E. (2015). Examining learners' perspective of taking a MOOC: Reasons, excitement, and perception of usefulness. Educational Media International, 52(2), 129-146.

Ma, B., Taniguchi, Y., \& Konomi, S. (2020). Course recommendation for university environments. In International educational data mining society.

McGoldrick, K., \& Schuhmann, P.W. (2002). Instructor gender and student registration: An analysis of preferences. Education Economics, 10(3), 241-260.

McNee, S. M., Riedl, J., \& Konstan, J. A. (2006). Making recommendations better: An analytic model for human-recommender interaction. In CHI'O6 extended abstracts on human factors in computing systems (pp. 1103-1108).

Nunez, J. L. M., Caro, E. T., \& Gonzalez, J. R. H. (2016). From higher education to open education: Challenges in the transformation of an online traditional course. IEEE Transactions on Education, 60(2), 134-142.

Osborne, J., Simon, S., \& Collins, S. (2003). Attitudes towards science: A review of the literature and its implications. International Journal of Science Education, 25(9), 1049-1079.

Ott, C., Robins, A., Haden, P., \& Shephard, K. (2015). Illustrating performance indicators and course characteristics to support students' self-regulated learning in CS1. Computer Science Education, 25(2), 174-198.

Pang, Y., Jin, Y., Zhang, Y., \& Zhu, T. (2017). Collaborative filtering recommendation for MOOC application. Computer Applications in Engineering Education, 25(1), 120-128.

Parameswaran, A., Venetis, P., \& Garcia-Molina, H. (2011). Recommendation systems with complex constraints: A course recommendation perspective. ACM Transactions on Information Systems (TOIS), 29(4), 1-33.

Parra, D., \& Brusilovsky, P. (2015). User-controllable personalization: A case study with SetFusion. International Journal of Human-Computer Studies, 78, 43-67.

Piao, G., \& Breslin, J. G. (2016). Analyzing MOOC entries of professionals on Linkedln for user modeling and personalized MOOC recommendations. In Proceedings of the 2016 conference on user modeling adaptation and personalization (pp. 291-292).

Pintrich, P. R. (2003). A motivational science perspective on the role of student motivation in learning and teaching contexts. Journal of Educational Psychology, 95(4), 667.

Potts, B.A., Khosravi, H., Reidsema, C., Bakharia, A., Belonogoff, M., \& Fleming, M. (2018). Reciprocal peer recommendation for learning purposes. In Proceedings of the 8th international conference on learning analytics and knowledge (pp. 226-235).

Ryan, R. M., \& Deci, E. L. (2000). Self-determination theory and the facilitation of intrinsic motivation, social development, and well-being. American Psychologist, 55(1), 68.

Schunk, D. H., \& Zimmerman, B. J. (2012). Motivation and self-regulated learning: Theory, research, and applications. Routledge.

Shell, D. F., Soh, L.-K., Flanigan, A. E., \& Peteranetz, M. S. (2016). Students' initial course motivation and their achievement and retention in college CS1 courses. In Proceedings of the 47th ACM technical symposium on computing science education (pp. 639-644).

Sweeney, M., Rangwala, H., Lester, J., \& Johri, A. (2016). Next-term student performance prediction: A recommender systems approach. arXiv preprint arXiv:1604.01840.

Tallón, V., Carvalho, P., Vinyals, H., \& Manzanares, M. (2014). Why do they choose an optional course? The rare case of teratology. European Journal of Dental Education, 18(2).

Tinto, V. (1997). Classrooms as communities: Exploring the educational character of student persistence. The Journal of Higher Education, 68(6), 599-623.

Tsai, C.-H., \& Brusilovsky, P. (2018). Beyond the ranked list: User-driven exploration and diversification of social recommendation. In 23rd international conference on intelligent user interfaces (pp. 239-250).

Zhang, H., Yang, H., Huang, T., \& Zhan, G. (2017). DBNCF: Personalized courses recommendation system based on DBN in MOOC environment. In 2017 international symposium on educational technology (ISET) (pp. 106-108). IEEE. 
Zheng, S., Rosson, M. B., Shih, P. C., \& Carroll, J. M. (2015). Understanding student motivation, behaviors and perceptions in MOOCs. In Proceedings of the 18th ACM conference on computer supported cooperative work \& social computing (pp. 1882-1895)

\section{Publisher's Note}

Springer Nature remains neutral with regard to jurisdictional claims in published maps and institutional affiliations.

Submit your manuscript to a SpringerOpen ${ }^{\circ}$ journal and benefit from:

- Convenient online submission

- Rigorous peer review

- Open access: articles freely available online

- High visibility within the field

- Retaining the copyright to your article

Submit your next manuscript at $\gg$ springeropen.com 